\title{
An Empirical Study on Employee Empowerment in TQM Practice in a Saudi Arabian Firm: A Case Study of Saudi Airlines
}

\author{
Fahad Masood Raza, Mohammed Ashi, \\ Fadhil Agusta, Abdulrahman Jalal \\ King Abdulaziz University \\ Facility of Computing and \\ Information Technology \\ Jeddah, Saudi Arabia
}

\author{
Syed Hamid Hasan \\ King Abdulaziz University \\ Facility of Computing and \\ Information Technology \\ Jeddah, Saudi Arabia
}

\begin{abstract}
Purpose: The ultimate aim of this research paper is to address notions related to TQM that assist in coping with problems affecting employee's empowerment, in terms of their practicing desires, proposals and alternative associated problems within Total Quality Management practice. TQM is an administration approach utilized mostly by organizations in the manufacturing field. TQM normally is shown as a framework which can facilitate in producing low price merchandise by applying numerous ways of management via a continuous refinement process. When the manager gives a worker the authority to make decisions whether in teams or individually, this act is called Employee Empowerment.
\end{abstract}

\begin{abstract}
Approach
A questionnaire was used for data collection, which addressed random employees in a Saudi firm. The sample was selected at random, with the criteria for participants being that they work at a Saudi firm. In addition, the number of respondents were 27 out of 30 of those invited to participate the questionnaire was sent individually to all participants in the research.

Findings: Fortunately, the findings show that Employee Empowerment is a widely known concept in Saudi firms, even though some local organizations do not know how to empower their employees in an effective way, still, the relationship between a manager and his team of employee is viewed to be beneficial especially as a way of improving work efficiency and customer satisfaction. Empowering employees is beneficial for a company as well for its staff, as empowering will create a situation where workers are able to make informed decisions which have a positive impact on the company's performance in their sector or field
\end{abstract}

Research limitations/implications: As an empirical study, this research was limited to a small sample of workers in Saudi firms, which was selected randomly. As a result, there might be a small degree of bias in respondents' replies. However, generally this research paper provides several comprehensive findings that can be further researched in the future

\section{Keywords}

Total Quality Management; Employee empowerment; Saudi Arabia;

\section{INTRODUCTION}

(TQM) is a modern management philosophy and an endless journey, not a destination. Total Quality Management is a new philosophy of management: it is never-ending process of continual development and improve, TQM is a series of structured steps leading to a form of organizational management that aims to improve the quality of a company's service and production. It was first applied in operations related to manufacturing, and it was used in that area for some years. The total in total quality management means that all of the company's members should make persistent attempts via structured efforts to improve the fulfilment of customer needs. All workers must be a part of the mission, vision, and plans so they can achieve continuous improvement. The success of TQM is not that simple from an organizational perspective. Moreover, it is almost impossible to have a full support from each member in the organization. In other words, some organization members will be skeptical about management's motives in that TQM might lead to greater demands of output and a reduction in manpower. When TQM was introduced for the first time in Japan, there were a lot of objections by the workforce. TQM requires a sustained commitment with clear Leadership and effective communication in order for it to be implemented effectively in organizations. Success is used as an indicator of the application of TQM in an organization. As mentioned earlier TQM is a modern management philosophy and an endless journey, not a destination, In addition, it is a group of different processes, systems, committed people, with clear communication and a customer satisfaction culture In fact, it was originally applied in manufacturing operations, and for some years was used only in that area. To clarify again, the totality of the concept refers to the notion that all employees ought to make persistent efforts in achieving substantial enhancement in customer related objectives such as assuring their satisfaction via systematic continuous efforts. All employees must be a part of the development of the strategic plan, which is known as the process of a group defining its own "VMOSA" (Vision-Mission-ObjectivesStrategies and Action plans) and in the pursuit of continuous improvement. TQM is not a way of getting the job done no matter the cost or the method, but it is a methodical path to improve quality and best meet customer needs. Examples of TQM are being implemented in an ad-hoc way. A lot of organizations are employing groups to influence the experience and knowledge of their workers to increase quality, decrease expenses and satisfy their customers. Every company has its own quality management system that plans and records objectives so it can improve their strategy. Quality management defines the path where organizations are managed in order to achieve efficiency, success, and competitive preeminence which are essential for long term organizational success. 


\section{TQM EVOULUTION}

In business, there are several important aspects of process such as the practical aspect, versatility aspect, and even the competitive aspect. In order to boost all of those three aspects; TQM is the best methodology to be implemented in any company. This is due to the fact that this method can make the significant improvements in all those three aspects simultaneously and with help eventually achieve the desired results which are a growth in customer satisfaction and loyalty. TQM is developed based on the customer's point of view and it has become advantageous for companies who are willing to apply it. As a matter of fact, if the customer becomes satisfied with one product, automatically it will increase their subsequent loyalty to the company's good and services. This was best described by Mahatma Gandhi when he stated once that actually customers are kings inside the business chain and every one of them has an important role, because every company has to serve them in order to earn profit and revenues for their proposed products. There are two main principles that play an important role within the TQM methodology for ensuring customers satisfaction factor: Namely management leadership and employees' empowerment. Beside these two main basic principles, there are aspects such as job satisfaction and also internal costumers' or employees satisfaction that will complete the important parts inside the TQM methodology.

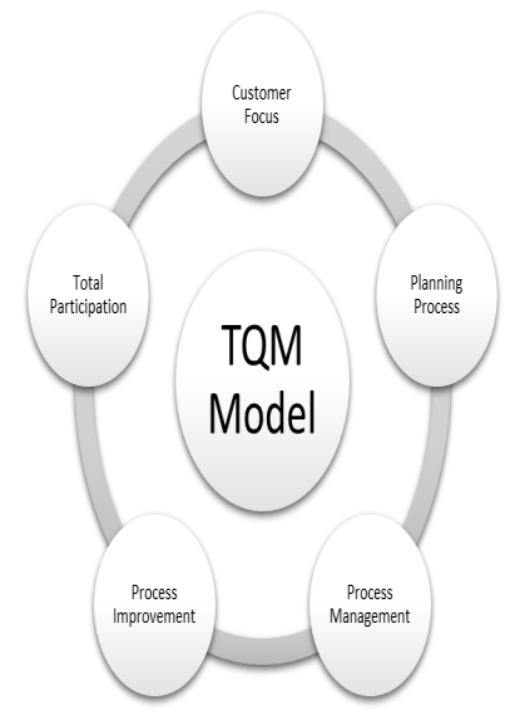

Fig 1: TQM Model

\section{TQM BASIC PRINCIPLES}

\subsection{Employees' Empowerment}

Terms like empowerment are usually used to connect each individual with their accomplishment within a large scale social connection that have some kind of terms and conditions or rules inside their working environment. This terms are becoming really important in TQM, because if the empowerment process is successfully applied, then surely the actions and character of employees will be better or will improve compared to before. When employees' actions and character are improved, the quality of the product will automatically increase. Based on one research at one company that already applies the TQM method, especially as regards employees' empowerment, there are considerable positive effects in terms of employees' commitment to the company, fulfillment of each task or job and even company loyalty. Inside the empowerment process, managers do not usually have to dedicate extra time and resources to supervising each of their employees. Because when empowerment process taking place, the management within a company do have to directly intervene in the process. For example, they need to carry out an ongoing evaluation of employees' abilities and performance when they are carrying out tasks within the TQM empowerment process. If one group is experiencing problems carrying out a task or solving a problem, then the company's management should intervene following the framework of the TQM empowerment process. In this way, employees' productivity can be improved by 30 percent. Besides carrying out the procedure, the management should dedicate resources such as time and money to any group that needs it, give some kind of prizes to every team that already achieves their target during the empowerment process. Management should also be flexible with target deadlines, they should not create undue stress within the process and they should be able to motivate and encourage the individual employees and the group as a whole within the empowerment process.

The Empowerment process is designed to raise employees' awareness of their strengths and potential and to provide them with the opportunity of running the company and at the same time enable them to grow and develop by helping them identify the best way to meet customer needs and by the end of the process be better able to achieve maximum customer satisfaction

\subsection{Empowerment is boundless}

Empowerment of employees is both boundless and limited. It should be constructed and planned to fulfill the goal in the TQM way. Workers must be aware of the company's overall mission statement and goals as laid down by the CEO but must also be able to work within the necessary parameters to achieve these goals.

\subsection{Give power to a Group of workers instead of single employee}

Empowerment should be carried out in teams not on individual employees one at a time. Even if an individual employee gets empowered this should be carried out with reference to his role within the group and positively affect the group's capacity to achieve company goals and targets by enabling it to identify and carry out the ideal way to achieve them., In addition the group should be able to independently identify and resolve specific issues related to the achievement of the task. Democratic teamwork is the best way to achieve this. They should be able to solve their issues within the framework that has been set up by their organization. The management should use a set of tools for gathering feedback on the results. Teams will not be isolated from the management as management's role is to equip and encourage and motivate them to carry out their assigned tasks. 


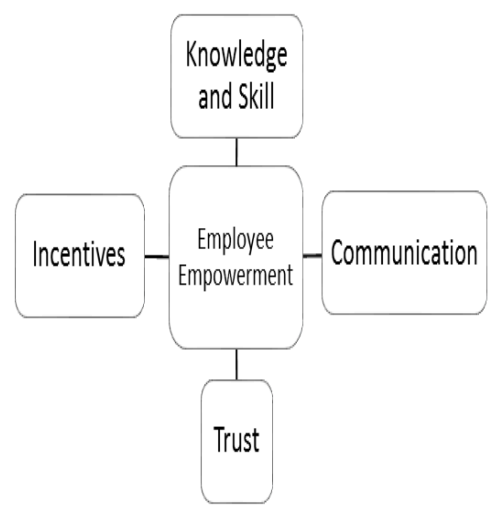

Fig 2. Empowerment model

In fig 2 you will see three constructs which have been suggested by Bowen and Lawler, and as a basis of empowerment, they added a another construct which is trust. Trust is known to have a great influence on the relationships between workers, management and customers

\subsection{The Needs Of Training For Empowerment}

\subsubsection{Training in Empowerment:}

Training can have a deep impact on employees and the company as a whole. Employees' needs must be borne in mind as must the context of the society in which the training will take place. Training should also refer to the wider context of international business and this perspective can help facilitate attitude change among trainees, enhance their expertise, broaden their outlook and experience and also inform decisions to be made regarding human resource management and changes in company structure and practice. Ongoing and continual training of HR staff is essential as it will increase their capacity to deal with problems, promote new ways of thinking outside the box and maximize the company's ability to plan flexible and effectively to deal with an ever-changing situation. Thus if economic factors, time constraints, the workers' abilities and capacity are all factored in, then highly positive results are achievable

\subsubsection{Plan and implement the training programs} Training is essential in today's organizations and should form part of a coordinated long term strategic plan. Any training program should be organized around clear principles with the ultimate goal being a growth in the organization's success and an improvement in their performance. Hence the organization may employ outside consultants to identify training goals and objectives and decide on and allocate resources necessary to achieve these goals and draw up and implement an achievable training schedule. So, the resources needed to establish and run the training programs can be split into two main areas: $\mathrm{HR}$ and material resources. HR includes elements such as the training team for example trainers, lecturers, tutors, and also the administrative team.

The material resources needed can be divided into physical resources and financial resources:

Physical resources: Such as workshops, labs, classroom, booklet, internet and computer, books.

Financial resources: including the initial investment and ongoing running costs

\subsubsection{Training desires Assessment}

Desires assessment is an organization technique which is designed to determine the basic desires to achieve the best outcome. It is essential to identify employees' development desires and to link them to a structured program with relevant input and activities so they can see the relevance of the training to their personal goals and objectives. This analysis also helps optimize the best training objectives, informs employee assessment criteria and thus helps the planning of specific training programs. Hence, careful selection of the participants is a priority along with an effective assessment and evaluation of the training undertaken.

Methods of desires assessment:

1. Assessment Model based on objective desires.

2. Assessment Model based on accord desires.

3. Assessment Model based on problem desires.

4. Assessment Model based on hybrid methods of evaluating desires.

\subsection{Empowerment in Catastrophe}

When the design of a product suffers modification, this might lead to increased customer satisfaction among a few customers but others may be dissatisfied. If customers complain this must be dealt with immediately for the sake of the organization's prestige and efficiency. The employee who is delegated to handle the complaint should be empowered to make the correct decision to resolve the situation immediately rather than passing the decision back to the company. Now that resolution may require the item being taken back to the service center for servicing or changing some parts free of charge or maybe replacing the whole product. These decisions are made to satisfy the consumer in line with the company's code of practice, and the employee acts on behalf of the company and this can only be in the company's best interest. It is also in the best interest of the customer and leads to greater customer satisfaction.

\subsection{Acknowledging employees' standpoint}

In order for employees to play an active role in coming up with innovations and suggestions for improving the company's performance there must be a tolerant open workplace culture. (Yahya Melham, 2004): Elements of this include:

- Having self-learning tools available for employees so they can benefit from greater skills and knowledge

- That the staff's expectations of management are met/ that management's expectations of staff are clearly stated.

- That staff believe they are able to succeed.

- That the learning curve of new skills etc. is borne in mind to allow staff sufficient learning time.

- Providing guidance and structure.

- Teaching employees newer skills bearing in mind the learning curve of any career.

- Assessing them in building report sharing information with staff 
- $\quad$ Giving them prompt, clear feedback and motivating them all through learning stages.

- Giving them alternatives in terms of methods to perform tasks and tackle related issues.

- Exhibiting sense of humor and be caring for them.

- Acknowledging personal progress and focusing on results.

\section{6 brain storming}

Carrying out regular brainstorming sessions with employees is one valuable way of encouraging good group dynamics.

Brainstorming participants, are encouraged to bring and share any thoughts and ideas that comes to their mind.

Using Brainstorming when the group need as many ideas as possible.

All members can freely share any ideas, and it will considered a valid idea. The most creative ideas come from apparently daft ideas and rejecting them limits and impedes the brainstorming process.

At the beginning Participants will not make any judgement or evaluate other's suggestions.

To remember all the outcome that came up in the brain storming, any ideas and suggestions should be recorded for future reference, preferably on an e-board, flip-chart or other medium which allows the participants to see and interact with them continually. Thus there is a long-term record of any outcomes.

After recording all the ideas and suggestions, the team will start the evaluation process. The team members will take every ideas individually and evaluate it, measuring the relative features of each idea. This procedure will be repeatedly carried out until the given ideas on the list have been dealt with, and then the best solution of the problem from that list can be chosen.

The brainstorming technique is an efficient tool for gathering employees' ideas and suggestions, especially if team-leaders are aware of possible pitfalls and are able to deal with them. Leaders can use brainstorming to facilitate and encourage employees' in line with the concepts of group thinking and group shifting. This two concepts can increase the efficiency of the brainstorming. Group thinking is the state that occurs when people who are in a group focus more on attaining a decision than on making a good decision.

Many factors can influence a group thinking, like the following:

- whole prescriptive leadership of the group,

- Inexperienced implementation of group decision-making techniques.

- Tolerance of criticism,

- Motivate to improve several alternatives. Do not make the group take a hasty decision by rushing them,

- Assign someone from the group to take the role of devil's advocate,

- $\quad$ Set a time limit to discuss the advantages and disadvantages of the ideas.
- Facilitate the participation of anyone who is an expert in the issue under discussion.

- Make a last chance discussion. When the group has reached a final decision, hold a second meeting in the next few days. In this way the group members will have more time to rethink the thoughts, ideas and the solution, and maybe come up with alternatives and second thoughts. The third meeting will allow the employees to freely share their second thoughts.If the brainstorming session fails to come up with ideas and solutions, then may the group have to reevaluate the problem?

\subsection{Improving suggestion schemes}

Empowering the workforce is about the cross-organizational sharing of full responsibility and power, assisting employees in developing themselves, facilitating innovation among them, encouraging them to take the initiative, and allowing them to make decisions independently, achieving either internal or external customers satisfaction (Mohanty et al., 1999). A suggestions system is the combination of processes that are meant for inducing, gathering, evaluating and accepting or dropping suggestions. Effective suggestion systems must embrace the following criteria:

- A formal response for all received suggestions.

- Immediate response for all received suggestions.

- Managements monitoring how each department isperforming in producing and replying to suggestions.

- Reports on System costs and savings must be made.

- No delays and prompt handling of recognitions and rewards

- Implemented good ideas suggested in schemes

- Personality conflicts are diminished.

Suggestion schemes are an example of the many available tools that are designed for encouraging staff to express their whole constructive ideas and thoughts for the total refinement of organizational performance (Raj Kumar et al., 2011). Therefore, employees' suggestions for numerous organizations that are willing to implement the TQM concepts are starting to become encouraged and accepted at all levels, not only being sought-after but also vital for staying competitive. As seen in all previously mentioned criteria, running such a system in organizations requires them more than just putting employees' suggestions in a box, approving a select few and rejecting the rest. On the other hand, a suggestions box must be replaced by a computer aided suggestion system, an approach that is being increasingly used. In this system, an acknowledgement may be provided online for each suggestion that is logged into the system. Additionally, small gift items may be given for each suggestion. Thus, all employees would feel proud of having taken part and grateful for this recognition of their participation in the organizational continuous development process.

\subsection{Improving individual suggestion}

In order to obtain valuable suggestions staffs ought to learn how to do two things. 
- Identify problems and formulate suggestions for improvement

- The ability to communicate their ideas clearly and concisely in a written form.

In order to increase the number of ideas for work place improvements generated by staff and the quality of those ideas, the following three steps must be implemented.

- Problem identification which involves identifying situations To begin with, no attempts are made to determine what is causing such problems, and there is no instantaneous assumption of the causes of problems either. Help and guidance must be provided to employees to realize that a problem should be systematically approached and in a progressive way. the process is all about scrutinizing, filtering and recruiting candidates for the resolution of problem situations existing in work place.

- The Significance of the problem must be researched, as if it is researched correctly or satisfactorily; it can stop the accumulated cost of resources dedicated to tackling the symptom rather than the root causes.

- Ideas development for solving the previously noted problem by eliminating pre-identified cause in prior steps is best accomplished by the idea development process. After formulating improvement ideas, employees ought to note them down using appropriate graphics for better illustrate their ideas.

- Higher management can assist their subordinates in improving their own suggestions through training and guiding them to act as follows:

- Providing a clear explanation of the current situation which causes the problem.

- Being specific and getting to the core of the suggested change with no introductions or justifications.

- Illustrating the proposed change using various tools in every case where this is appropriate in order to clarify each aspect of it.

\section{EVALUATIONS AND RATING SUGGESTIONS}

Employees are always interested and eager to make suggestions for workplace improvements. However, the final analysis and evaluation of proposed idea is the responsibility of managers who must decide its feasibility. Hence, this might impact or prevent employees from participating in the organizational development process. There are some facts that may be taken into considerations when evaluating suggestions. Here are some, examples Suggestions must be fully evaluated with the person who suggested them in person and with questions about each point. Patience is required in order to find out their exact view point and help must be given to enable them to fine-tune and improve their suggestions.

- Some suggestions may seem to be poor or irrelevant. However, they may still contain some good ideas once refined but outdated or bad suggestions need to be vetted.
- It is important to be kind to the participants giving their suggestions for the first time and to build their confidence and skills for future suggestions. If possible, try to accept their suggestions fully or partially bearing in mind the possible need for future revision

- $\quad$ Suggestions from employees with long experience in writing suggestions must be precisely evaluated and incorporated into a set of higher goals.

- Consider their level when their suggestions are evaluated as if you underestimate their abilities they would not experience the challenge that would let them improve. On the other hand, if they are overestimated, their creativity and initiative will be drained.

- Expedite the evaluation of suggestions as participants will be worried about and waiting for the feedback. Otherwise, let them know if you are going to be late with the feedback. (Naidu, et al., 2006)

- Once done, inform the participant and review the evaluation results in person. If his/her ideas are not accepted, make certain to include some phrases of encouragement. Remember to include some positive comments along with results when giving written feedback.

- Do not forget to compliment all contributors for their ideas and work. Generally, suggestions are the invention of its authors with their supervisors.

A formal grading mechanism must be introduced in order to evaluate a suggestion scheme. Quantifying feedback results must be done with this rating system. It must also incorporate at least the following features:

- When assessing the feasibility of employee suggestions, criteria are the most important factors. Here we ought to starting asking these questions, what benefits do we expect from a suggestion? How long will it take before we start witnessing benefits? And how successful were the suggestions submitted from a certain individual or a team in the past?

- Criteria used in an organization must be alike organization-wide, ensuring consistent and fair evaluation, although they may be different from an organization to another. However, a numerical score or rating must be associated with each criterion. This is a key step for the whole process due to the fact that it demands judgment, common sense, and comprehensive knowledge related to the situation in the question and being open-minded.

- Take into account the fact that different criteria vary in importance. The individual rating for each one of the criteria is multiplied, determining its weighted score by assigning it to a weight-factor

- $\quad$ Regarding the summed points, total, and conversion scales. The suggestion total score equals the summation of all weighted scores. Later, a level, a category or a grade will be assigned to the suggestion as per its total score. 


\section{HANDLING POOR SUGGESTIONS}

Discretion and courtesy must be exercised when rejecting a suggestion in order to maintain participating employees' interest and morale. Factually, an effective suggestion system would not entirely reject poor suggestions. Some steps on how to effectively handle poor suggestions are listed below:

- Listening attentively and giving the participator a chance to thoroughly describe his/her suggestion. In this way aspects and details of the suggestion can be more fully described than on the written form with extra insight being gained from the employee's perspective.

- Demonstrate your appreciation to employees for their suggestions as this will undoubtedly inspire them to participate further in suggestion schemes in the future. On the contrary, you must reply to invaluable or unaccepted suggestions with statements such as that "even though your suggestion is not viable, your time efforts are much appreciated and your ideas are valued. We are hoping to hear from you again".

- Never reply with excuses or blame the organization, managers, executives or anybody else. Just sincerely clarify the logic behind rejecting the suggestion i.e. it is not viable, in a manner that would assist staff in making better and more feasible suggestions in the future.

- Request every employee to give their further feedback. Maximizing feedback helps promote mutual understanding.

- Never fully accept poor ideas. However, a compromise solution may be possible for suggestions that can be altered making some portions of it beneficial, thus, using all or parts of it to add value to the organization.

- Case Study: a Saudi Airlines TQM tool for improving employees participation in organizational development:

An example of an effective TQM practice that has been recently implemented in Saudi Airlines recently is the "Tawasol" internal social network. This intranet site is a Microsoft Yammer enterprise social network that is especially built for private communication within Saudi Airlines. No one can gain access to it except employees' as the only way to access it is to use their corporate email credentials. Using "Tawasol", employees are kept informed of all organization related news and related topics such as the Saudi transformation project, crisis management, newspapers and the media, staff discounts, personal skills and talents, and the overall aviation news. Moreover, they can add topics, ideas, and suggestions for all topics that can be viewed by all company staff, including the CEO. Additionally, they might chat with their colleagues in real-time communications sharing ideas, and related files and documents.

Since Tawasol has been released, it has dramatically improved or has become a key feature of the TQM function in the company. A good illustration of this is the newly internally publicized campaign by the Sales Department, who requested all employees regardless of their kind of work or position to suggest an idea that will benefit their first flight to the newly launch rout to Maldives adding ancillary revenue to it. Actually, many suggestions were submitted. However, only one employee was awarded a prize for his innovative idea, encouraging a cross-organizational collaboration and competition. In addition, another perfect example is when Saudi adapted the fingerprint authentication machines for time management of employees, an employee using "Tawasol" suggested enabling some motivational and welcoming messages for every time an employee clocks-in or out. Obviously, this positively impacted employees' performance as they nowadays start their working days with a positive mindset and a smile. One more example is that the organization often internally publish corporate bulletins or decrees regarding some amendments in corporate policies or procedures and on more than one occasion, employees had the chance to reject what is published partially or fully, noting their reasoning as this is a must. Most of the time executives follow back giving their feedbacks and matters seriously valuing employees' be points and opinions positively thus cross-organizational collaborations.

\section{AWARDS AND REWARDS}

Surpassing managers' expectations of the fulfilment of the performance requirement is presumed to be very significant in every organization. Thus, recognizing achievements of internal and external customers is vital in TQM environment. Some very important notes on awards and rewards in TQM are that when selecting a winning idea to be rewarded, it should be done bearing in mind specific factors. In other words, we should only reward those with an outstanding performance. An award must be achievable by everyone organization-wide and not limited to a group of people. The winner should be recognized by all employees, either are contestants or not, demonstrating the authenticity of the competition and the award. Selecting the employee with the best performance is due to many attributes, namely, commitment, creativity, flexibility, adaptability, determination, responsibility etc.

Awarding individuals for their praiseworthy service should be a normal practice and not be an obstacle, for example in teamwork environments. Organizations must reward teams as much as it can, embracing teamwork. Moreover, they must emphasize and recognize employees as a team and not as individuals. Therefore the employees will continue to work and perform in a harmonious way. Organizations must choose the most suitable award. For instance, the prize can be appreciation in a yearly meeting, certifications, trophies, and monetary rewards. In fact, monetary rewards can play a major role in motivating employees and boosting their performance; and consequently, leading to substantial benefits as regards holistic organizational performance (Aguinis et al., 2013). Award ceremonies must be announced periodically at all organization levels. Equally, all teams exceeding the performance measure should be eligible for the awards. Awards type and time period must be uniform and not always changed by organizations. Therefore, this will noticeably increase raise employees' satisfaction and morale. Only unbiased and genuine awards should be granted as such awards will drive others to follow.

\section{REFERENCES}

[1] S. Thamizhmanii, S. Hasan, A review on an employee empowerment in TQM practice, Journal of Achievements in Materials and Manufacturing Engineering 39/2 (2010) 204-210

[2] Raj Kumar Dixit Garg T.K. Garg, (2011),"TQM success factors in North Indian manufacturing and service industries", The TQM Journal, Vol. 23 Iss 1 pp. $36-46$ 
[3] Seung-Bum Yang Sang Ok Choi, (2009),"Employee empowerment and team performance", Team Performance Management: An International Journal, Vol. 15 Iss 5/6 pp. $289-301$

[4] http://study.com/academy/lesson/employeeempowerment-definition-advantages-disadvantages.html.

[5] M. Milflora Gatchalian, People empowerment: the key to TQM success, The TQM magazine 9/6 (1997) 429-433

[6] - A.F. Kennedy, L. Schleife, Team performances measurement: A system to balance innovation and empowerment with control, Advances in Management 16 (2007) 261-285

[7] M. Dudek-Burklikowska, D. Szewieczek, The PokaYoke method as an improving quality tool of operations in the process, Journal of Achievements in Materials and Manufacturing Engineering 36/1 (2009) 95-102

[8] J. Michalska- $\square$ wiek, Enterprises' evaluation according to the polish quality awards, Journal of Achievements in Materials and Manufacturing Engineering 36/2 (2009) 199-206

[9] Mohanty, R. P., and R. R. Lakhe. "Factors Affecting TQM Implementation: Empirical Study in Indian
Industry." Production Planning \& Control 9.5 (1998): $511-20$.

[10] Yahya Melham, Antecedents of customer contact employee's empowerment, Employees relations 26/1 (2004) 72-93

[11] Naidu, N. V. R., K. M. Babu, and G. Rajendra. Total Quality Management. New Delhi: New Age International (P), 2006. Print.

[12] http://tentouchapps.com/grafio/solutions-area/tqmdiagram/

[13] D.E. Bowen, E. Lawler, Empowering service employees, Slogan Management Review (1995) 73-88- Faculty of Mechanical and Manufacturing Enginee University Tun Hussein Onn Malaysia,

[14] 86400, Parit Raja, Batu Pahat, Johor, Malaysia Corresponding author: E-mail address: thamizhm Received 21.12.2009; published in revised form 01.04 .2010

[15] Aguinis, Herman, Harry Joo, and Ryan K. Gottfredson. "What Monetary Rewards Can and Cannot Do: How to Show Employees the Money." Business Horizons 56.2 (2013): 241- 